
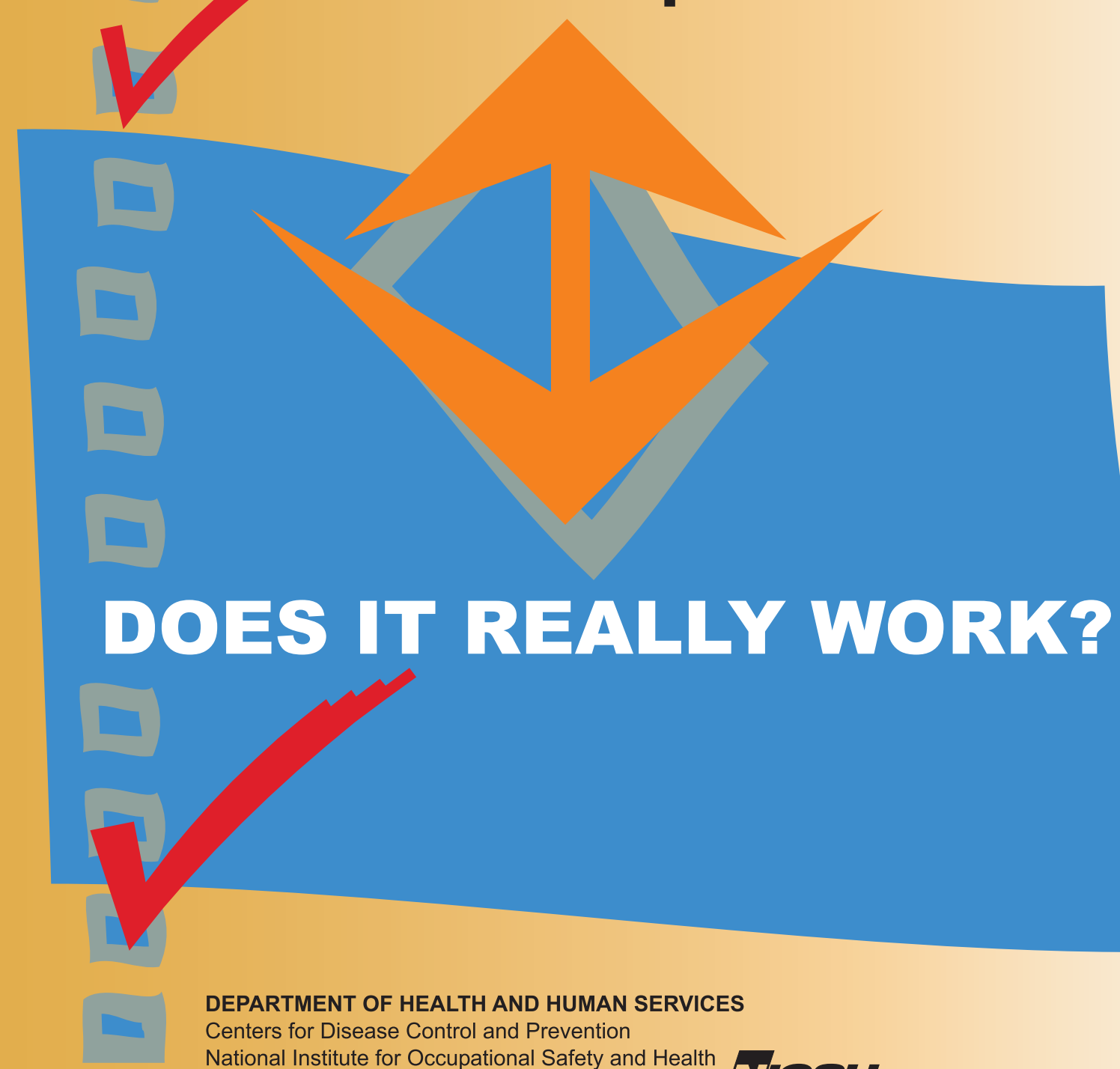

DEPARTMENT OF HEALTH AND HUMAN SERVICES

Centers for Disease Control and Prevention

National Institute for Occupational Safety and Health

Niosh 


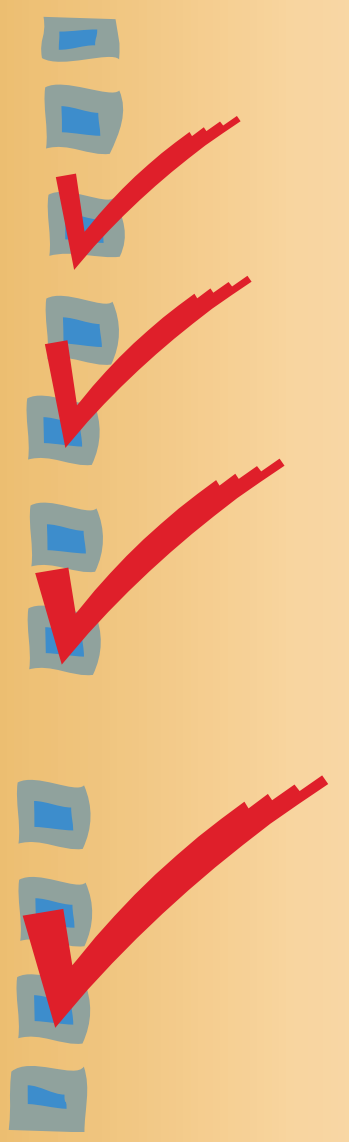




\title{
DOES IT REALLY WORK? How to Evaluate Safety and Health Changes in the Workplace
}

\author{
Prepared by the \\ Intervention Effectiveness Research Team \\ of the National Occupational Research Agenda
}

DEPARTMENT OF HEALTH AND HUMAN SERVICES

Centers for Disease Control and Prevention

National Institute for Occupational Safety and Health 


\section{Disclaimer}

Mention of any company or product does not constitute endorsement by the National Institute for Occupational Safety and Health (NIOSH). In addition, citations to Web sites external to NIOSH do not constitute NIOSH endorsement of the sponsoring organizations or their programs or products. Furthermore, $\mathrm{NIOSH}$ is not responsible for the content of these Web sites.

\section{Ordering Information}

To receive documents or other information about occupational safety and health topics, contact NIOSH at

NIOSH-Publications Dissemination

4676 Columbia Parkway

Cincinnati, OH 45226-1998

Telephone: 1-800-35-NIOSH (1-800-356-4674)

Fax: 513-533-8573 - Email: pubstaft@cdc.gov

or visit the NIOSH Web site at www.cdc.gov/niosh

DHHS (NIOSH) Publication No. 2004-135

March 2004

SAFER • HEALTHIER • PEOPLE ${ }^{\text {TM }}$ 


\section{A Message from the Director}

This guide is intended for managers interested in improving their business by ensuring the health and safety of workers. It invites managers to look carefully at changes they have made to improve occupational health and safety in the workplace, and to ask the question, "Does it really work?"

When you evaluate safety and health changes, you will find that some are successful, some need to be modified, and some have no positive impact on the workplace. Obtaining this valuable information is vital to any business manager, and is the primary focus of this guide. A systematic process is needed to evaluate both a plan or idea for change as well as any implemented intervention. This requires a collaborative effort by both management and employees that should be celebrated, along with any successes in protecting their health and safety at work.

The guide is divided into the following three sections: case studies that illustrate the collaborative effort of employers and workers to evaluate occupational safety and health changes in the workplace; four easy steps outlining how to conduct your own evaluation of safety and health changes in the workplace; and a list of additional resources about these evaluations.

The authors of this guide are members of the Intervention Effectiveness Research Team of the National Occupational 
Research Agenda (NORA) effort, sponsored by the National Institute for Occupational Safety and Health (NIOSH). They are an interdisciplinary team of business, academic, labor, and government professionals who believe that the best solutions for workplace health and safety problems are those that have been adequately and thoroughly evaluated. I encourage you to try the methods described in the guide which will enhance your evaluation skills, and add value to your business and your role as a manager and leader.

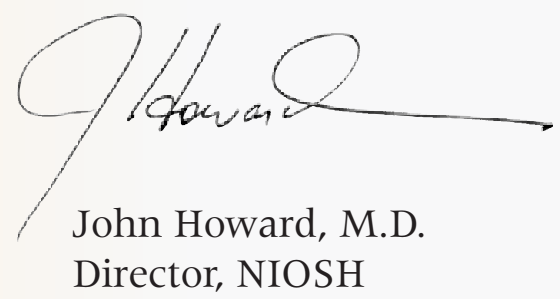




\section{Acknowledgements}

This guide is a product of the National Occupational Research Agenda Intervention Effectiveness Research Team. We have been inspired and guided by the authors of the Guide to Evaluating the Effectiveness of Strategies for Preventing Work Injuries: Lynda Robson, Harry Shannon, Linda Goldenhar, and Andrew Hale. We are also grateful to those who conducted the case studies we describe: Michael Smith, James Collins, Leonard Banco, Scott Earnest, and those who worked with them. We appreciate the graphic and Web design work done by Vanessa Becks, Anne Stirnkorb and Rohit Verma for this project as well as the editorial work of Susan Feldmann, Amanda Gust and John Diether. 


\section{Preventing Back Injuries}

In Nursing Homes

Reducing Strains In Meat Processing
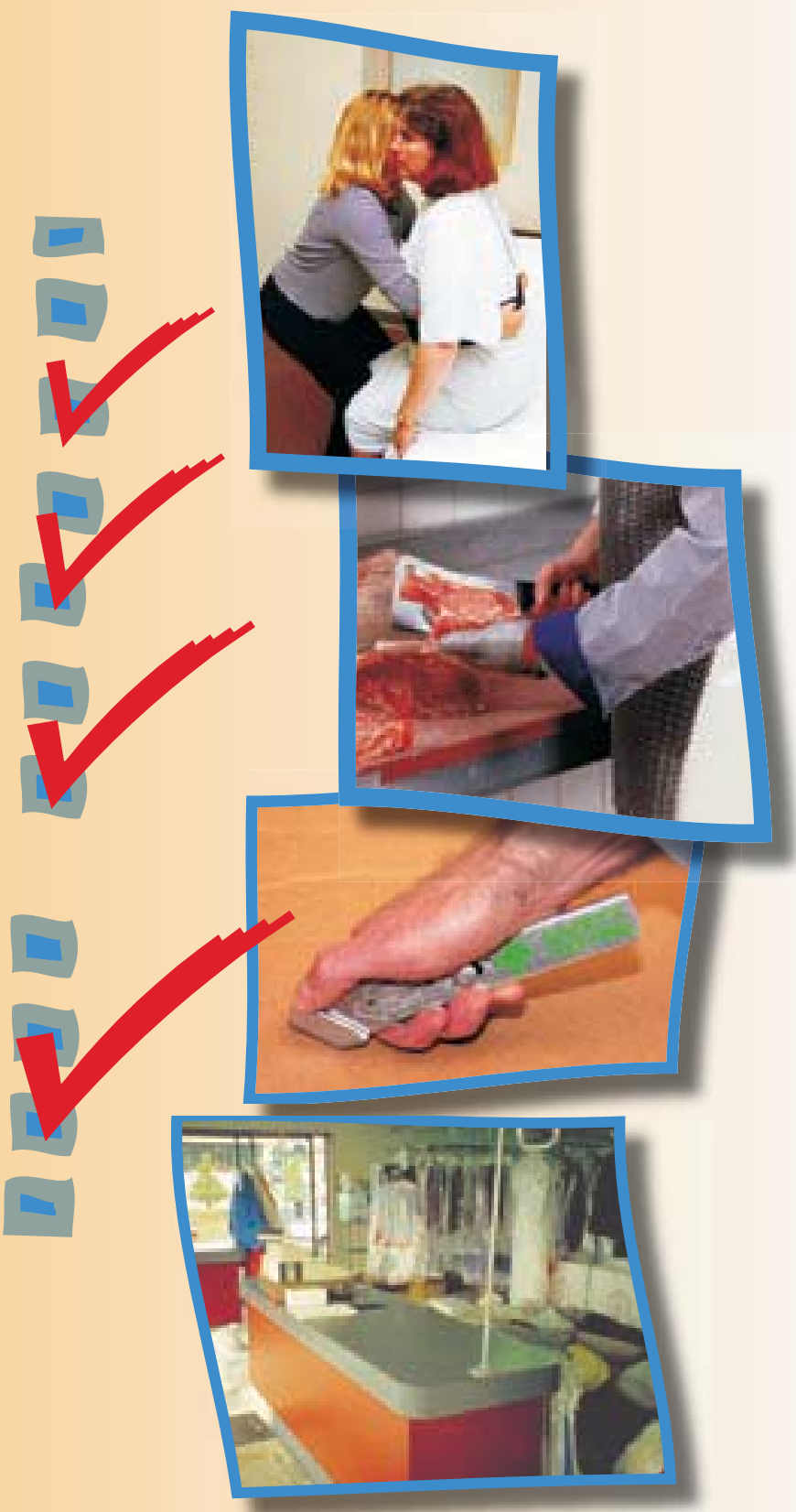

\section{Stopping Cuts}

In a Grocery

Controlling Chemicals

In the Air 


\section{Introduction}

Businesses are continuously making safety and health changes in the workplace. But when making those changes, successful employers and managers want to be sure that they really work. What were the results? Was the change an improvement? Here are some examples of positive outcomes that employers use:

- reduced employee injury and illness

- increased employee satisfaction

- improved safe work practices

- reduced absenteeism

- reduced workers' compensation costs or rates

- increased productivity

- improved workplace air quality

Measuring the results of workplace safety and health changes benefits employers and employees because both gain confidence that the change results in a safer workplace. Since most changes occur by trial and error or in stages, information about the effectiveness of each stage is naturally helpful to the process. These changes often result in increased productivity and demonstrate that employee safety and health can be a good investment. Employees must be involved throughout the selection of safety changes and their measurement. 
Here are examples of how several different companies evaluated employee safety and health changes:

\section{Case 1: Preventing back injuries in nursing homes}

Back injury is a common problem in the health care industry. A company that owned and managed five nursing homes decided to do something about it.

After reviewing employee injury records for the previous three years, the nursing home managers and safety personnel determined that most back injuries occurred while transferring residents-such

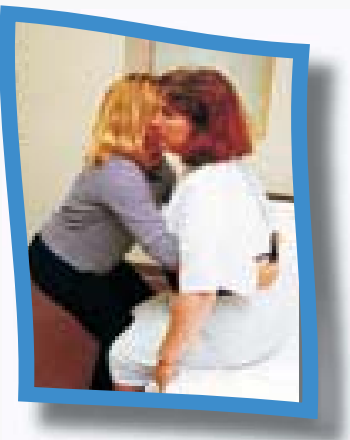
as from their beds into chairs. These injuries were the most common (50 per year on average) and cost the most in workers' compensation (about $\$ 165,000$ per year). The records also showed that nursing aides and orderlies were the employees most likely to be injured.

A team of workers and managers developed an employee survey to help identify the most physically demanding tasks. Workers identified three types of resident transfers as "very heavy":

- Transferring residents on and off the toilet

- Transferring residents in and out of beds and chairs

- Bathing and weighing residents 
The managers of the nursing homes were aware of several types of lifting equipment that could assist in resident transfers. They asked three manufacturers of lifting equipment to provide samples for a 30-day trial. The managers included the employees from the beginning. They asked the nursing aides and orderlies to test the various types of lifts. They selected one type, which was purchased for permanent use. The cost to equip all five nursing homes was \$143,000. By allowing staff to evaluate and select the equipment, the managers demonstrated confidence in staff judgment, encouraged teamwork, and increased use of the lifting equipment.

After using the equipment for 3 months, the original survey was given to the staff again. The tasks previously identified as "very heavy" were now identified as "not at all heavy." During the next 2 years, an average of 25 injuries occurred per year, half as many as before the lifts were introduced. The cost of these injuries was about $\$ 60,000$ per year, cutting workers' compensation costs by almost two-thirds. Managers estimated that the original investment in the equipment (including training costs) was recovered within the first 2 years of use. 
Three measures suggested that the change was successful: employees rated transfers as less stressful than before the equipment purchase, fewer injuries occurred, and workers' compensation costs declined. Although this evaluation did not rule out other possible reasons for these improvements, it provided strong evidence that the introduction of lifting equipment prevented back injuries at the nursing homes.

See the sample questionnaire from this study on the next page.

\section{Case 2: Reducing strains in meat processing}

A large meat processing plant developed an intervention to reduce the high incidence of body aches and pains experienced by plant workers. They instituted an ergonomics program. The managers conducted an ergonomics evaluation to help figure out how to redesign jobs that presented strain hazards for workers' backs, arms, and hands.

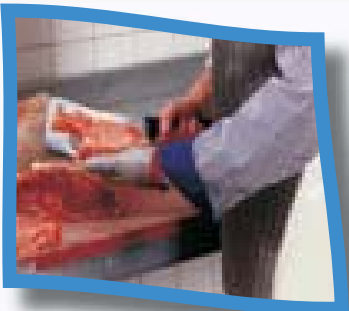

The consultant found that meat cutting, meat wrapping, and meat packaging were high-risk jobs because they had shortcycle repetition, little variety, and production pace determined by machine, not the employee. These factors are known to be related to over-use injuries and job stress.

The consultant recommended work station and tool redesign, improved work methods, and job rotation. Management and 


\section{Nursing Survey on Patient Handling Tasks}

What are the most physically demanding duties you perform when working with residents? For each of the following, mark the answer that best describes how much effort is required. For any task that you do not perform, mark the box, "Do not do this task."

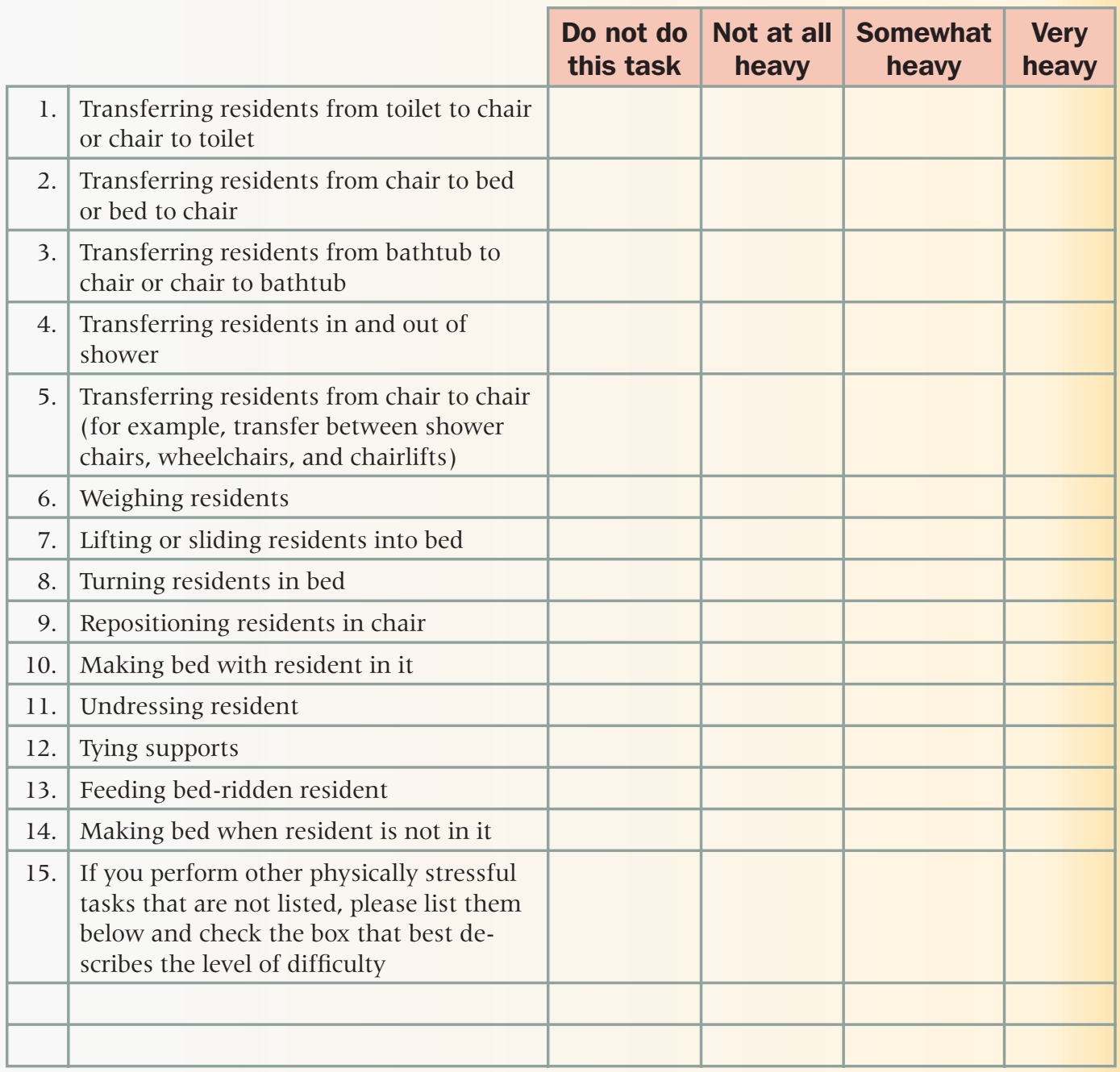

Source for Case 1: Collins J, Wolf L [2001]. Intervention program for transferring residents in nursing homes. Washington, DC: Presentation to the 2001 National Occupational Research Agenda Symposium. 
representatives of the United Food and Commercial Workers International Union organized discussions with the workforce regarding these recommendations. For 2 months, weekly worker brainstorming sessions were held in each department to

- address the appropriateness of the consultant's recommendations for change,

- improve the recommendations and provide additional ones, and

— help determine the best ways to implement the changes.

Results from the sessions were presented and discussed with other workers.

After careful consideration, management and labor agreed to try rotating cutting, wrapping, and packaging jobs among

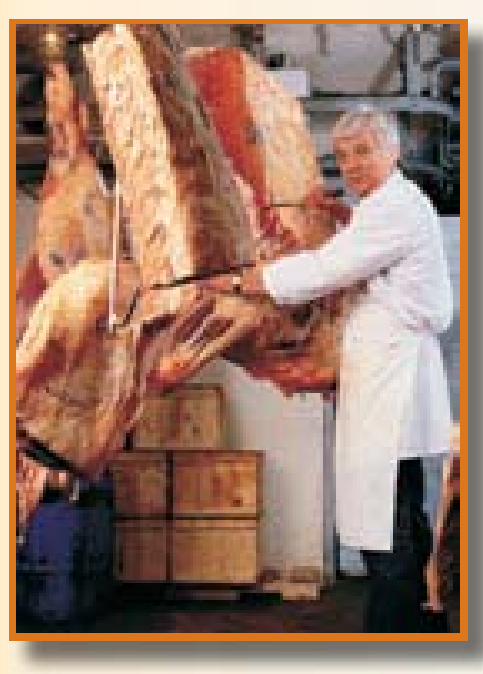
workers. This rotation was designed to reduce exposure to any one repetitive task and to increase task variety and skill development. It also gave all workers the opportunity to perform meat cutting, which was considered a more prestigious position. It is important to note that pay rates were hourly (not piece rate) and were negotiated through collective bargaining for the entire line; that is, all three job classifications were paid at the same hourly rate. Thus rotating jobs on the meat processing line had no effect on wages. 
Workers completed a survey of health status and working conditions before the change was implemented and again a year later. The consultant also interviewed workers and supervisors before and after the change.

All workers reported that overall working conditions improved under the job rotation program. Meat wrappers and packagers were most satisfied with the program because it allowed them to perform more challenging tasks. Meat cutters liked the program because it gave them a break from the more physically demanding task of cutting meat, but they disliked having to work in the lower-prestige jobs. Supervisors were satisfied with the change because it allowed greater flexibility in job assignments when key workers were absent and the machine pacing of the majority of the work was left intact. The job rotation program also allowed the workers to better tolerate the demanding work conditions.

Improvement was also measured by a reduction in recordable injuries and illnesses. (Cumulative trauma is an occupational illness under OSHA definitions. Recordable cases require medical treatment beyond first aid or result in restricted work activity or days away from work and are assessed continuously.) Before the intervention, recordable cases averaged 15.7 per 100 full-time workers, per year. Two years after the intervention, recordable cases were reduced to 6.8 per 100 full-time workers.

The reduction in injuries and illnesses 2 years after the intervention is a good indication of long-term effectiveness of the intervention. In this example, once the company began improvement activities, the management went far beyond anything specified in the agreement. 
This case study is also important for what was not changed:

- The machine pacing of the majority of the work was left intact.

- High productivity and high workload were maintained.

- The job rotation program effectively enabled the meat processing workers to better tolerate the demanding conditions of cutting because this assignment was timelimited each day.

In this case, management, the union, and workers responded in a proactive and positive fashion, and made improvements that benefited all the workers.

See sample questionnaire from this study on the next page.

\section{Case 3: Stopping cuts in a grocery store chain}

A grocery store chain in Connecticut examined employee injury records for 4 years. The records showed 199 cuts involving case cutters. Of those, 116 (58\%) occurred among workers who had been employed less than one year, and of those, 42 had been employed 3 months or less. Soon after, the company started working with local medical professionals. With their help and the help of the employees, the company found a case-cutting tool 


\section{Current Health Questionnaire}

Please answer the questions listed below regarding your health. We want to know how you have felt this past week, including today. Do not put your name on this questionnaire, but be sure to indicate your job title and department at the bottom. No one will know how you answered the questions. This information will help us to improve your working conditions. Thank you!

Please mark the column that indicates how often you have experienced each of the following during the last week.

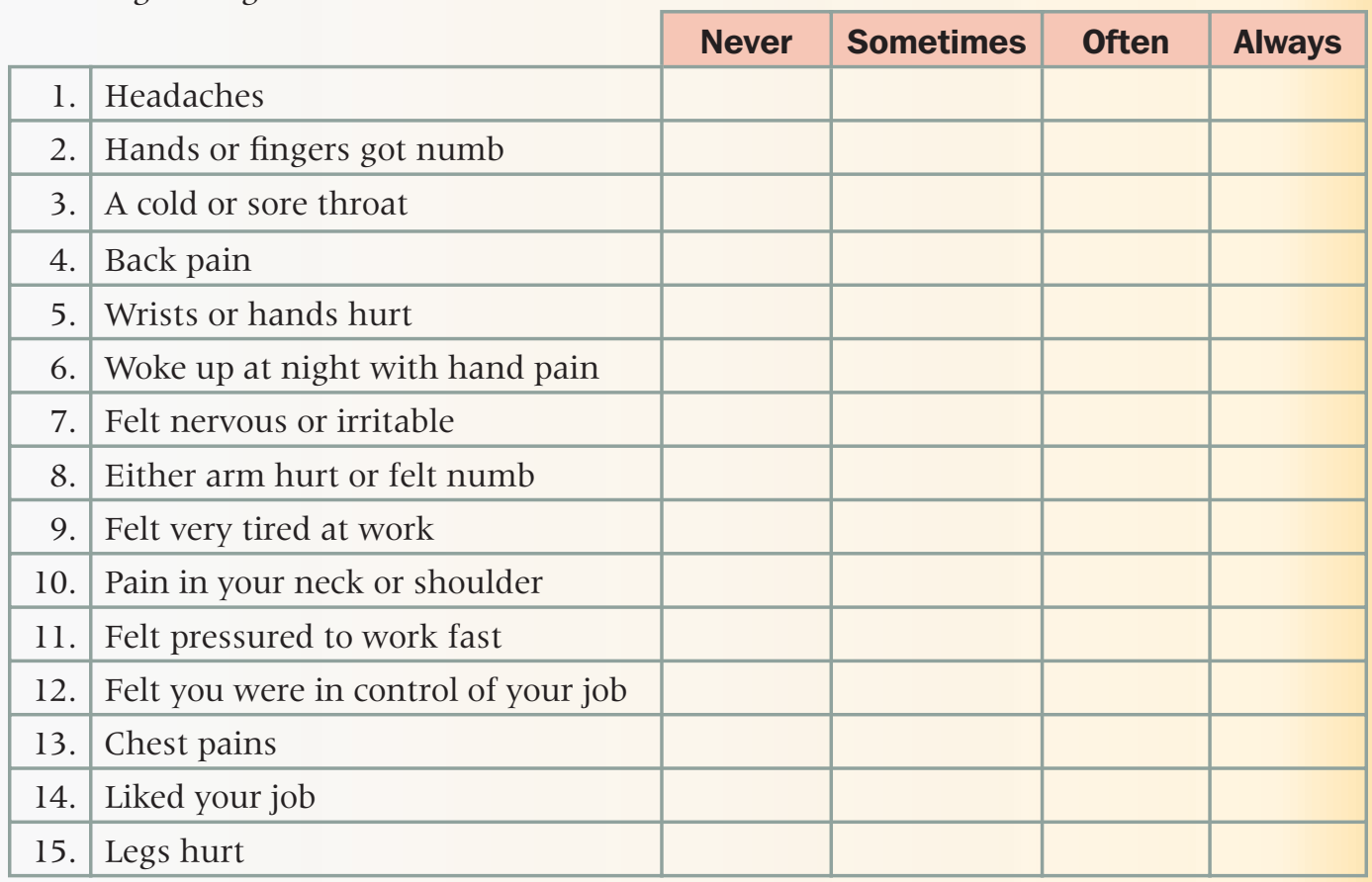

Please fill in your job title and department below. Thank you for your help.

Job title

Department

Source for Case 2: Smith MJ, Zehel D [1992]. Case study no. 9: a stress reduction intervention programme for meat processors emphasizing job design and work organization (United States). Conditions of Work Design $11(2): 204-213$. . 
on the market that featured a safety guard. A few employees were asked to try the new tool. They reported that they liked the tool and that it would probably not reduce production. The company decided to evaluate the tool's effectiveness.

With the medical researchers, a team of store managers and workers studied the results of using the new cutting tool in nine company stores. In 3 of the stores, employees received the new safety case cutters and 15 minutes of training in their appropriate use. In 3 other stores, employees kept their old case cutter but got 15 minutes of training in how to use them safely. In the last three stores, employees kept their old tools and received no training.

\section{Comparison}

new tool and training vs. old tool and training vs. old tool

The team decided to compare the three groups on the following:

- Injury rates: the rate of case-cutting injuries

- Financial gains and losses from the change: for cutters and training

- Financial gains and losses from injuries: for workers' compensation and loss of time on the job

After one year, the results showed that the new tool and training group had the fewest injuries, with no compensation or time-loss costs after the change. They also had slightly lower 
Cut injuries by group before and after introduction of the new cutter

\begin{tabular}{|c|c|c|c|c|c|}
\hline \multirow[b]{2}{*}{ Group } & \multicolumn{2}{|c|}{ Before change } & \multicolumn{2}{|c|}{ After change } & \multirow[b]{2}{*}{$\begin{array}{l}\text { Injury rate } \\
\text { change }\end{array}$} \\
\hline & $\begin{array}{c}\text { Number of } \\
\text { injuries }\end{array}$ & $\begin{array}{c}\text { Number of } \\
\text { injuries per } \\
50 \text { full-time } \\
\text { workers }\end{array}$ & $\begin{array}{l}\text { Number of } \\
\text { injuries }\end{array}$ & $\begin{array}{c}\text { Number of } \\
\text { injuries per } \\
50 \text { full-time } \\
\text { workers }\end{array}$ & \\
\hline $\begin{array}{l}\text { New tool } \\
\text { and training }\end{array}$ & 48 & 4.7 & 6 & 1.2 & $-74 \%$ \\
\hline $\begin{array}{l}\text { Old tool and } \\
\text { training }\end{array}$ & 39 & 3.3 & 8 & 1.8 & $-45 \%$ \\
\hline No change & 79 & 3.6 & 19 & 2.0 & $-44 \%$ \\
\hline
\end{tabular}

\section{Gains (+) and losses ( - ) per 50 full-time workers compared to the "no change" group}

\begin{tabular}{lccccc}
\hline & Supplies & Education & $\begin{array}{c}\text { Workers' } \\
\text { comp }\end{array}$ & Time lost & Total \\
\hline $\begin{array}{l}\text { New tool } \\
\text { and training }\end{array}$ & $+\$ 41^{*}$ & $-\$ 333$ & $+\$ 317$ & $+\$ 107$ & $+\$ 132$ \\
$\begin{array}{l}\text { Old tool and } \\
\text { training }\end{array}$ & $+\$ 134^{*}$ & $-\$ 362$ & $+\$ 188$ & +98 & $+\$ 58$ \\
\hline
\end{tabular}

*"No change" group supply costs were higher due to high number of old cutters that were made available to employees in that group.

Source for Case 3: Banco L, Lapidus G, Monopoli J, Zavoski R [1997]. The safe teen work project: a study to reduce cutting injuries among young and inexperienced workers. Am J Ind Med 31:619-622. 
training costs than the old tool and training group. The old tool and training group also had fewer injuries than the no-change group. The company eventually adopted the tool for the entire chain.

\section{Case 4: Controlling chemicals in the air}

Perchloroethlylene (PERC) is used in most dry-cleaning shops in the United States. It is an excellent solvent for removing dirt, but overexposure to it can harm workers' health. PERC is a carcinogen that can damage the liver and kidney. Overexposure can also cause headaches, dizziness, and memory loss. PERC exposure happens as workers load and unload clothes from drycleaning machines. When high concentrations of PERC are released from the machine, exposures can adversely affect workers in the shop as well as others. For example, in some cases, especially in large cities, PERC emissions have resulted in complaints and lawsuits from adjacent neighbors and businesses.

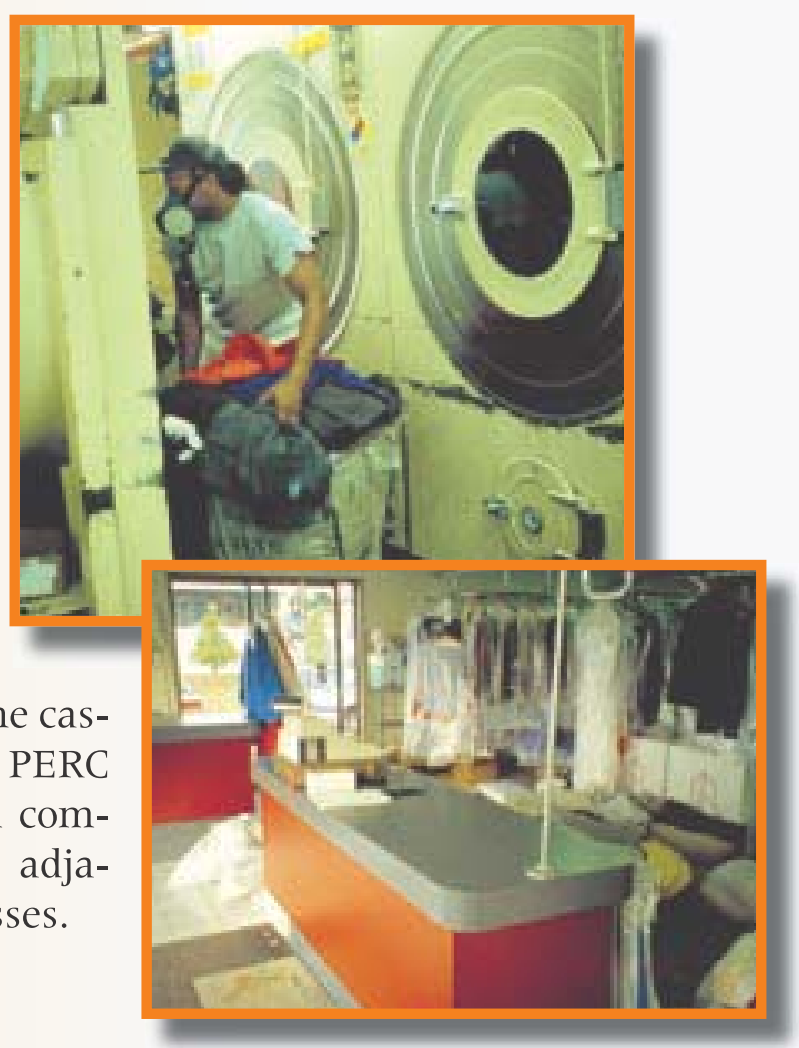


In one shop with fewer than 10 employees, the shop owner and the employees were worried about PERC, but they were not sure how high their exposures were. They found out that PERC concentrations in the air around the machines could be measured. With some outside help, various types of air sampling equipment were used to measure PERC concentrations in parts per million. Several workers volunteered to wear air samplers to evaluate their exposures to PERC. The air samplers have a small, battery-operated pump that sucks air through a filter that is clipped onto clothes near the worker's face. This air sampling occurred during several work days to make sure any unusual events in the loading and unloading processes were averaged out. Several workers were sampled for the same reason-to average out any individual differences in work practices.

After several days of air sampling, the data were compared with maximum PERC exposure allowances for workers. Videos were made for the workers showing that their highest PERC exposures occurred while they were near the dry-cleaning machine. They learned that in many cases, the machine operators were exposed to amounts of PERC that exceeded acceptable workplace standards. To reduce their exposure, the owner put a special exhaust filter onto the machine. Then they used the air sampling equipment again. The filter reduced some exposures by about $90 \%$. The filter cost about $\$ 5,000$ compared to the $\$ 60,000$ cost of the dry-cleaning machine.

Source for Case 4: Earnest GS, Ewers L, Ruder A, Petersen MR, Kovein RJ [2002]. An evaluation of retrofit engineering control interventions to reduce perchloroethylene exposures in commercial dry-cleaning shops. Appl Occup Environ Hyg 17(2):104-111. 


\section{Form A Team}

\section{Collect Relevant Data}

Analyze Data

\section{Share Your Results}

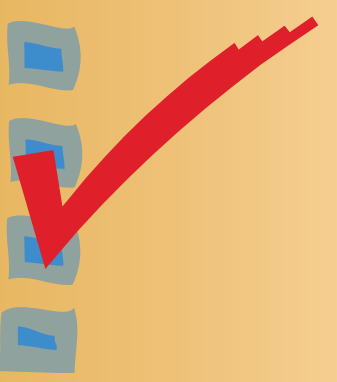




\section{Steps for Evaluating Safety and Health Changes}

Evaluation should be a part of workplace changes from the start, through the process of finding an idea, trying it, testing to see if it results in positive outcomes, and if it does, adopting it. You can evaluate a plan or idea for change just as well as you can evaluate the actual change. Evaluation isn't necessarily expensive or complicated. Here are four steps to follow:

\section{Form a team}

Evaluations are best done by a team. When forming a team, keep in mind that workers are often the best source of information about the workplace.

Wherever possible, the team should include people who are

- affected by the safety and health change,

- responsible for implementing and maintaining the change, and/or

— involved in future decisions about changes.

The team should start by defining the problem as clearly as possible. The more specifically that the problem is defined, the better that a solution can be designed to fit, and the easier it is to test the solution.

Brainstorm a solution for the problem and one or two ways to measure the effectiveness of the change. Using more than one way to measure the change will increase your confidence in the results. 


\section{Collect relevant data}

Collect accurate data on workplace safety and health. Consider collecting three kinds of data: conditions before the change, information about how the change was put in place, and what happened after the change was made. Good records of how the change was made will help if you want to do it again because they tell you what happened. Data on the outcome will tell you whether to bother doing it again.

How, how often, and when should you collect data? One way is to measure an outcome (like employee injuries) before and after the change. Typically, injuries are infrequent occurrences; therefore, you may need to collect data for quite awhile before and afterwards to make sure that any changes you detect are real. On the other hand, if you are measuring changes in employee knowledge and attitudes after a training session, you may not need to measure for as long a period of time. You may measure immediately before the training, right after the training, and then one or two more times 3 months to 1 year after the training.

Another model for gathering information is to arrange the change so that it does not affect everyone in the operation at one time. By introducing the change to several different groups over a period of several months or a year, you can get a better idea of effectiveness. Simply measure all the groups (those who receive the change immediately and those who receive it later) at regular intervals as you gradually introduce the change to the selected groups. This takes more effort, but it gives you added 
confidence that any detected effects are from the change and not some other event.

What to measure depends on the following:

- Expected outcomes-what will happen as a result of the safety and health change? Whatever you expect-reduced injuries or absenteeism, increased productivity, -measure those things.

- Nature of the safety and health changes-for example, if the change is plant exhaust ventilation, then you may want to measure air quality before and after. If the change is increased rest breaks for employees, then you may want to measure productivity. If the change is new training, then you may want to look for performance indicators or success/failure rates.

- Opportunity - think of measurements that are practical. Remember that someone or something has to collect and analyze the measurements you choose.

Here are some simple ways of collecting data. If you use more than one of these methods to measure each change, you will be more certain of the results.

$\square$ Records

$\square$ Surveys

$\square$ Interviews

$\square$ Focus groups

$\square$ Observation

$\square$ Environmental

measures 


\section{Records}

Several types of records can provide data on the effectiveness of safety and health changes.

Useful data include the following:

- Injury frequency and rates

- Workers compensation costs

- Lost workdays and absenteeism due to work-related injuries

- Profit and loss

- Air sampling data, noise readings

- Production errors or waste

- Cost of respiratory equipment or ear protection

Records should be checked for completeness and accuracy before they are used.

\section{Surveys}

Surveys are useful for determining workers' perceptions both before and after a change:

Pre-change assessment

- What is working well?

- What is working poorly?

- Where in the work process are there delays in production?

- Where can quality be improved? 
- What procedures place workers at risk of illness or injury?

- What changes can be made to correct existing problems?

Post-change assessment

- Is the change effective?

- How has the workplace been changed?

- Are things better or worse?

- How could the change be improved?

You can also use surveys to measure knowledge, attitudes, and behaviors. Write the survey in such a way that all those who read or hear it will understand the questions. Test the survey with a sample of workers before using it to find out whether the questions are understood as you intend. Surveys can be distributed in a number of ways: in person, with paychecks, by mail, e-mail, Internet, or a combination of methods. Followups are usually necessary to increase participation and get the completed forms back.

For more information on using employee surveys, click on www.iwh.on.ca/archive/pdfs/eval_gde.pdf (Guide to Evaluating the Effectiveness of Strategies for Preventing Work Injuries). Once there, go to page 60 .

It is always best to encourage the participation of your entire workforce in a survey. Often surveys lead to planned change and survey participants are more likely to feel a sense of ownership in the change. However, if you cannot afford to survey everyone in a very large workplace, select a sample that represents all important groups such as departments within a hospital or plant, 
and be sure to include all the groups that are anticipated to be included in the workplace change.

It is very important to establish a system that assures the confidentiality of each person's responses, including both the collection and the reporting of the survey data. Anonymous surveys and results can go a long way toward encouraging employees to provide honest feedback on the survey.

\section{Interviews}

Interviews are one-on-one, face-to-face conversations. In these conversations, the interviewer(s) asks the same set of questions to a number of people, but talking to only one person at a time. Interviews require more time and resources than surveys, but provide more detailed information. Record interviews so that statements can be accurately reviewed and analyzed. Since interviews usually involve fewer people than surveys, you should interview a range of people who represent all the important groups associated with the change. One drawback to interviews is that the data can be challenging to analyze because it may be quite detailed or because there may be extra material that is not important to the evaluation.

\section{Focus groups}

Focus groups involve gathering information and opinions that are "focused" on one subject from a small group of people (about 8 to 10 per group). These group discussions often provide insights that might not emerge in interviews. Focus groups can be used in all stages of making a safety and health change-from planning to determining effectiveness. You may 
want to recruit participants with similar characteristics (such as job classification) since group discussions often thrive on common experience. Hold separate group discussions when you want to solicit opinions from supervisors and the employees they supervise. Assuring the confidentiality of such discussions is essential.

Below are tips for planning and conducting a focus group:

- Develop a list of discussion topics ahead of time.

- Determine the amount of time to be spent on each topic. (Good discussions usually require about 1 1/2-2 hours.)

- Design questions in such a way that they encourage discussion. (Don't ask questions that get short answers like "yes" or "true.")

- Start the session with an "ice breaker" that gets everyone to talk. Make sure that everyone knows that they are expected to contribute.

- Have an experienced note taker attend. If you can get all participants' permission, record the session on audio or video tape.

- Afterward, review the notes, tape, or transcript and summarize major points. If a transcript is prepared, be sure to substitute fictional names for the names of actual participants.

\section{Observation}

Watching how people behave in the workplace before and after you make a safety and health change may give you good 
evidence about the effects of the change. Observation allows you to collect continuous information about how the work is done and about the effects of the change in workplace procedures.

Follow these guidelines when you observe people:

n Decide in advance which behaviors to look for.

- Vary your observations so that they are a more-representative sample of people and time periods.

- Record your observations. This may involve watching people in person and recording their actions on a checklist. It could also involve recording people on video tape and then categorizing their actions later with the checklist.

- Whether you record people on tape or not, explain what you're doing and why, and get their permission before you observe. Even though they know you're watching, most people will quickly forget about you. But the presence of an observer may affect what people do.

For more information on carrying out interviews focus groups, and observations click on www.iwh.on.ca/archive/pdfs/eval_ gde.pdf. Once there, go to page 67.

\section{Environmental measures}

Some safety and health changes are designed to improve the physical work environment. Two examples are noise baffles around loud equipment and extra ventilation to remove contaminants. Environmental measures can help determine 
whether these changes are effective. Environmental measures include air sampling and noise monitoring. This type of data gathering may require people with special equipment and training, but the data they can collect may help pinpoint the value of the change.

For more information about environmental measures, click on www.iwh.on.ca/archive/pdfs/eval_gde.pdf. Once there, go to page 62.

\section{Analyze data}

Data must be systematically analyzed to determine whether the changes are effective. Data analysis can be simple or complex depending on the questions asked, the completeness of the data, and the experience of the evaluation team.

When analyzing data:

- Allow team members to interpret findings independently.

- Compare members' findings with the goals set by the team.

- Arrive at conclusions about the change on the basis of the findings.

- Summarize the results in such a way that everyone involved understands them.

After the initial analysis is complete, you may want to continue collecting data about the change. These data can serve as baseline measures for future interventions. They are also useful for determining the long-term impact of the change. 


\section{Share your results}

First, share your results with those affected by the change. The more you tell them about what you did and what you found, the more they will support your conclusions and your future efforts to evaluate safety and health changes in the workplace. A good way to start the feedback process is to hold work-group meetings to present the results. Don't worry about drawing conclusions from the results, just start with the basic findings. This approach will permit everyone to begin thinking about what the results suggest. You could also post the results in worker areas like break rooms, locker rooms, and cafeterias.

During the data analysis and results steps, be careful to maintain confidentiality. Breeches in confidentiality can affect your credibility. Do not report results in such a way that individual responses can be identified. This is especially important where there are workgroups of 3-6 people. In such circumstances, it may be necessary to report results for several workgroups, combined. 


\section{What Does It All Mean?}

Making changes in the workplace is not easy. Take time to think about how you are going to evaluate your changes. Thinking through your options will provide you with the information necessary for making better decisions in the long run.

Evaluation can be very complicated or it can be relatively simple. Although the simplest methods may be seem less "scientific," they can still give you good information for making some important decisions. After a simple evaluation, you can decide to expand the intervention to other work groups in your company, or consider making additional changes.

Improving worker safety and health, as well as increasing productivity, is a continual process:

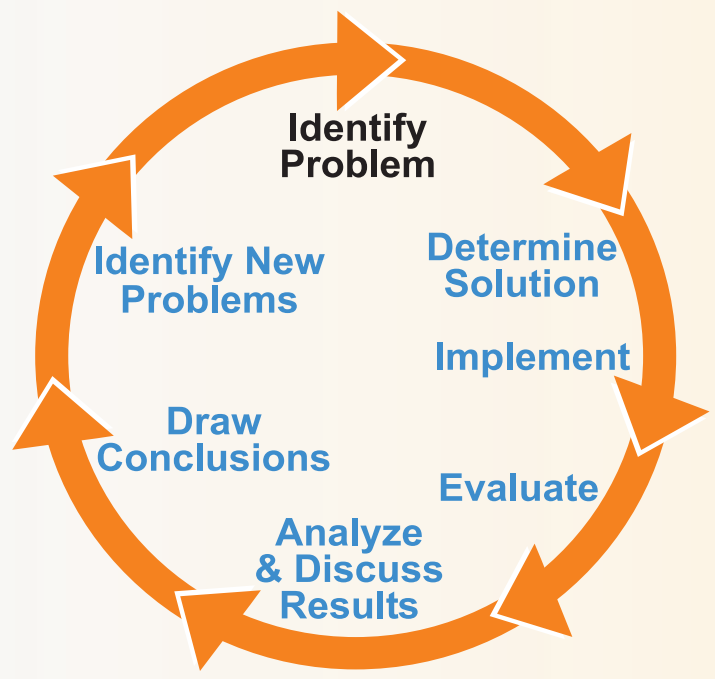


Your organization may benefit from evaluations done by others and vice versa. Share your evaluation results with local and national trade associations and labor unions. Some international organizations are developing solutions databases to make such information available worldwide.

The National Institute for Occupational Safety and Health (NIOSH) would like to know about your success stories. Let NIOSH know how you have made your workplace safer and healthier. You may contact Ray Sinclair at (513) 533-8172 or RSinclair@cdc.gov to discuss your successes.

\section{Suggested Reading}

Guide to Evaluating the Effectiveness of Strategies for Preventing Work Injuries: How to Show Whether a Safety Intervention Really Works. 2001. NIOSH Publication No. 2001-1 19. This book is available free of charge from the NIOSH Publications Office (1-800-35-NIOSH) and on the Internet at www.cdc.gov/niosh.

How to Conduct Your Own Survey by Priscilla Scant and Don A. Dillman. 1994. Published by John Wiley and Sons, New York.

Case Studies in Safety and Productivity 2000. National Safety Council www.nsc.org or 1-800-621-7619. Reports from 12 different organizations on the results of safety and health efforts in the workplace.

Injury Prevention: Meeting the Challenge. The National Committee for Injury Prevention and Control, American Journal of 
Preventive Medicine, 1989, Volume 5, Number 3. This book is for people who want to take action to prevent injuries. It focuses on how resources can be applied in a sound manner to evaluate the effectiveness of injury prevention efforts.

Business and Industry Topic Interest Group of the American Evaluation Association-web page: www.evaluationsolutions.com/aea-bitig/. This site has links to 31 organizations that may have helpful information including the American Management Association, the American Compensation Association, the American Society for Quality, and the Association for Manufacturing Excellence. 


\section{DEPARTMENT OF HEALTH AND HUMAN SERVICES}

Centers for Disease Control and Prevention

National Institute for Occupational Safety and Health

4676 Columbia Parkway

Cincinnati, OH 45226-1998

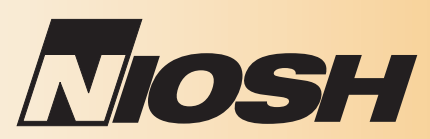

Delivering on the Nation's promise:

Safety and health at work for all people

through research and prevention

SAFER • HEALTHIER P PEOPLE

To receive NIOSH documents or more information about occupational safety and health topics, contact $\mathrm{NIOSH}$ at

1-800-35-NIOSH (1-800-356-4674)

Fax: 513-533-8573

E-mail: pubstaft@cdc.gov

or visit the NIOSH Web site at www.cdc.gov/niosh

DHHS (NIOSH) Publication No. 2004-135 